\title{
Air ions and mood outcomes: a review and meta-analysis
}

Vanessa Perez ${ }^{1}$, Dominik D Alexander ${ }^{2}$ and William H Bailey $^{3^{*}}$

\begin{abstract}
Background: Psychological effects of air ions have been reported for more than 80 years in the media and scientific literature. This study summarizes a qualitative literature review and quantitative meta-analysis, where applicable, that examines the potential effects of exposure to negative and positive air ions on psychological measures of mood and emotional state.
\end{abstract}

Methods: A structured literature review was conducted to identify human experimental studies published through August, 2012. Thirty-three studies (1957-2012) evaluating the effects of air ionization on depression, anxiety, mood states, and subjective feelings of mental well-being in humans were included. Five studies on negative ionization and depression (measured using a structured interview guide) were evaluated by level of exposure intensity (high vs. low) using meta-analysis.

Results: Consistent ionization effects were not observed for anxiety, mood, relaxation/sleep, and personal comfort. In contrast, meta-analysis results showed that negative ionization, overall, was significantly associated with lower depression ratings, with a stronger association observed at high levels of negative ion exposure (mean summary effect and 95\% confidence interval (Cl) following high- and low-density exposure: 14.28 (95\% Cl: 12.93-15.62) and 7.23 (95\% Cl: 2.62-11.83), respectively). The response to high-density ionization was observed in patients with seasonal or chronic depression, but an effect of low-density ionization was observed only in patients with seasonal depression. However, no relationship between the duration or frequency of ionization treatment on depression ratings was evident.

Conclusions: No consistent influence of positive or negative air ionization on anxiety, mood, relaxation, sleep, and personal comfort measures was observed. Negative air ionization was associated with lower depression scores particularly at the highest exposure level. Future research is needed to evaluate the biological plausibility of this association.

Keywords: Mood disorders, Depression, Air ionization, Ion exposure, Epidemiology, Systematic review, Negative ion, Positive ion

\section{Background}

Several experimental human studies on air ion exposure and mood ratings have been published throughout the years. While their evidence is inconsistent, the findings have increased awareness of mood alterations possibly associated with such exposure. Ions are ubiquitous, whereby any molecule with an unbalanced electron to proton ratio results in a net positive or negative electrical charge [1]. Air ions are produced from alterations

\footnotetext{
* Correspondence: wbailey@exponent.com

${ }^{3}$ Exponent, Inc., Health Sciences, Center for Exposure Assessment and Dose Reconstruction, 17000 Science Drive, Suite 200, Bowie, MD 20715, USA

Full list of author information is available at the end of the article
}

in the atmosphere and weather phenomena, by natural radioactivity, and by combustion processes [2,3]. They are also generated by air ionizers sold commercially and by corona activity on the surface of high voltage conductors of transmission lines.

Some experimental research indicates that exposure to negative air ions is linked to reduced depression severity [4-8], lower psychological stress [9], less anxiety [10], and enhanced well-being [11-14]. Others suggest that exposure to positive air ions may be associated with feelings of unpleasantness, irritability, and heightened

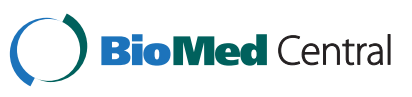


anxiety [15-17]; while some have found no mood alterations associated with air ionization $[18,19]$.

Historically, evidence of psychological measures and air ionization has been equivocal because research findings use heterogeneous experimental protocols evaluating diverse study populations; use various methods to measure mood-related outcomes; and use inadequate experimental design and procedures including control over relevant exposures [20]. Diagnostic trends for classifying mood disorders and technological advancements in environmental therapies (e.g. air ionization systems) have likely influenced study findings. Furthermore, most studies have tested relatively small study populations. To the best of our knowledge, no current review has summarized the possible effects on mood and well-being attributed to air ionization. We therefore conducted a structured literature review to evaluate human experimental studies on positive and negative air ion exposure and ratings of depression, anxiety, mood states, and subjective feelings of mental well-being. In addition, we quantitatively examined negative air ionization and depression symptom severity using meta-analysis.

\section{Methods}

\section{Literature search and study identification}

A structured literature review performed for the Minnesota Environmental Quality Board on the biological/health effects attributed to air ions and direct current transmission lines was used to identify the historical literature up to 1982 [21]. We further conducted a structured literature search using Medline (PubMed) to identify experimental studies published between 1 January 1982 and August, 2012 on air ionization and depression, anxiety, mood states, and subjective feelings of mental well-being in humans. ProQuest DIALOG was used to retrieve studies from the environmental and behavioral sciences, engineering, and other technical databases, including Elsevier, Biobase, and Embase.

Identical search strings for PubMed and ProQuest DIALOG referenced the exposure (air ions, charged aerosols, corona ions, atmospheric ions, ionization, ionized air, heavy ions, light ions) and outcomes of interest (depression, anxiety, mood, activation, personal comfort, relaxation, sleepiness). We manually reviewed reference lists in all retrieved articles for related publications. Thirty-three English-language studies published between 1957 and 2012 met our inclusion criteria (Table 1).

Inclusion criteria consisted of experiments among subjects exposed to negatively- or positively-charged small air ions, or both; studies published in the English language; and studies that reported associations between ionization and mood indicators (e.g., depression, anxiety, mood states, and reports of mental well-being). No restrictions on the number of subjects evaluated in each study were required. Animal studies, letters to the editor and editorials, references not reporting original data, and studies with no relevant exposure or outcome were excluded.

\section{Data extraction and statistical methods}

Qualitative information (study population/design, ion polarity/concentration, exposure duration) and quantitative data (mood indicator effects) were extracted. Studies were consolidated qualitatively into four outcome categories: activation, anxiety, and mood; relaxation/sleep; personal comfort ratings; and depression.

A meta-analysis was performed on five studies [4,6-8,22] of negative air ionization and depression symptom severity as measured using the 29-item Structured Interview Guide for the Hamilton Depression Rating Scale, Seasonal Affective Disorders (SIGH-SAD), which consists of the 21-item Hamilton Depression Rating Scale and the 8-item Atypical Scale. Forest plots from random effects modeling [23] were generated to estimate weighted group mean differences in depression scores, 95\% confidence intervals (CIs), and corresponding $p$-values for heterogeneity. Of note, using the random effects analysis, the weighted mean is defined as the sum of each study effect size multiplied by its weight (i.e., the inverse of the within-study variance plus the between-studies variance) divided by the sum of the weights. The variance of the weighted group mean difference is defined as the reciprocal of the sum of the weights. The data from Terman and Terman [6] were extracted from their Figure one; exact values have been requested from the authors. Depression score data before and after exposure to low density ions were also requested from Dauphinais et al. [24] for possible inclusion. Sensitivity analyses were performed to examine data robustness. Publication bias was assessed using funnel plots, the Begg rank correlation test, and Egger's regression analysis. All analyses were performed using the Comprehensive MetaAnalysis software (version 2.2.046; Biostat, Englewood, NJ). Additional dose-response relationships were evaluated by plotting exposure duration by depression score mean differences and their corresponding 95\% CIs in Microsoft Excel (2010).

\section{Results}

Studies meeting inclusion criteria are summarized in Table 1. All studies included adults only and sample sizes ranged from 4 to 124 participants. Apart from the studies that evaluated ion effects on patients with some form of depression, six studies [11,14,19,25-27] also evaluated the influence of ions on mood states of persons with varying health conditions. Collectively, the findings from these six studies did not provide contrasting results from those studies that included only healthy subjects. Most studies examined negative air ionization only 


\section{Table 1 Study characteristics}

\section{Author and year Study objective}

Silverman and

Evaluate effect of negative and positive ions on

Kornblueh 1957[27], the human electroencephalogram and sleep

McGurk, 1959[17]

Evaluate effect of negative and positive ions on Crossover experiment self-reported feelings of comfort

Yaglou, 1961[19]

Evaluate effect of negative and positive ions on Crossover experiment relaxation

Yaglou, 1961[19] Evaluate effect of negative and positive ions on Crossover experiment relaxation and sleepines

Assael et al., 1974[1 1 $]^{\mathrm{b}} \quad$ Evaluate effect of negative ions on human Crossover experiment electroencephalogram

Albrechtsen et al., Evaluate effect of negative and positive ions on Crossover experiment $1978[37]^{\mathrm{b}, \mathrm{c}}$ human well-being and mental performance

Charry and Evaluate effect of negative and positive ions on Crossover experiment Hawkinshire, 1981[15] $]^{\mathrm{a}}$ mood

Hawkins, 1981[38], c Evaluate effect of negative and positive ions on Crossover experiment subjective well-being and comfort

Tom et al., 1981[34] $]^{\mathrm{a}, \mathrm{b}} \quad$ Evaluate effect of negative ions on human performance and mood

Randomized controlled trial

Buckalew and Rizzuto, Evaluate effect of negative ions on subjective 1982[12], b feelings of mood and psychological state

Randomized controlled trial

Dantzler et al,

1983[25]

Evaluate effect of positive and negative ions on Crossover experiment somatic symptoms and mood changes

Baron et al., 1985[28] ${ }^{\text {a }} \quad$ Evaluate effect of negative ions on self-reported Crossover experiment affect/mood

Deleanu and Evaluate effect of negative ions on psychiatric

Stamatiu, 1985[29] a,b,d symptoms

xperimental (no contro group)

Gianinni et al.,

1986[16]

Evaluate effect of negative and positive ions on anxiety, excitement, and suspicion

$987[30]$

innegan et al., 1987

[40]

Hedge and Collis, $1987[18]^{\mathrm{a}}$ excitement

Crossover experiment

Crossover experiment

Crossover experiment

Study population

Total sample size

Not reported

10 healthy adults and 2 additional subjects with

chronic stationary neurologic conditions

Single-blind (subjects) 10 college-aged males

Single-blind (subjects) 25 healthy adults (age range: 22-51)

Single-blind (subjects) 6 arthritic patients (age range: 30-62)

Double-blind

10 healthy participants (age range: 20-65) and 20 10 subjects receiving tranquilizers

Single-blind (subjects) Study 1: six women (age range: 20-30) chosen Study 1: 6 Study 2: at random; study 2: 12 subjects (age range: 19- 12 45) selected because they appeared to be most sensitive to ionization

Single-blind (subjects) 85 adults (age range: 18-60; mean age: 30)

Double-blind

Study groups based on three areas of variable air ionization levels within the building (area 1 : 20 women; area 2: 32 adults; and area 3: 54 adults)

Area 1: 20

Area 2: 22 Area 3: 54

Double-blind

56 adults (age range: 17-61; mean age: 23)

Double-blind

Two groups of 12 paid male volunteers matched on age, education, physical condition and smoking habits (age range: 20-30; mean age: 22.8)

Double-blind

9 patients with bronchial asthma (age range: 35-64)

Single-blind (subjects) 71 male undergraduate students

Not reported

112 patients with neurasthenias, psychoses, or personality disorders

Double-blind

14 university-affiliated volunteers

Double-blind

12 adult male volunteers

14

Single-blind (subjects)

26 adults working within 5 different rooms of an office building

28 healthy women (age range: 19-58) 
Table 1 Study characteristics (Continued)

\section{Lips et al., 1987[13] $]^{\text {b,c }} \quad$ Evaluate effect of negative ions on well-being} and comfort

Misiaszek et al., $1987[14]^{a, b}$

Evaluate effect of negative ions on manic behavior and sleep

Reilly and Stevenson, Evaluate effect of negative ions on anxiety 1993[33] $]^{\text {S }}$

Terman and Terman, Evaluate effect of negative ions on seasonal $1995[6]^{d}$ depression

Watanabe et al. $1997[35]^{\mathrm{a}, \mathrm{c}}$

Terman et al., $1998[8]^{\mathrm{b}, \mathrm{d}}$

Evaluate effect of negative ions on mood and pleasantness

Evaluate effect of negative ions on sleep and seasonal depression

Nakane et al., 2002[10] ${ }^{\text {a }}$ Evaluate effect of negative ions on anxiety Iwama et al., 2004[39] ${ }^{\text {b }} \quad$ Evaluate effect of negative ions on tension

Goel et al., 2005[22] $]^{\text {b,d }} \quad$ Evaluate effect of negative ions on sleep and chronic depression

Goel and Etwaroo, Evaluate effect of negative ions on depression, $2006[5]^{\mathrm{a}, \mathrm{b}, \mathrm{d}} \quad$ total mood disturbance, and anger

Terman and Terman, Evaluate effect of negative ions on sleep and 2006[7] $]^{\mathrm{b}, \mathrm{d}}$ seasonal depression

Gianinni et al. 2007[26]

Malcolm et al. $2009[32]^{a, b}$ Evaluate effect of negative ions on manic states Evaluate effect of negative ions on positive affective memory

Evaluate effect of negative ions on seasonal depression
Crossover experiment

Double-blind

Experimental (phase I: no control group; phase II: with-in subjects, repeated measures)

Crossover experiment

Randomized controlled trial

Crossover experiment

Crossover experiment

S

Crossover experiment

Not reported

Randomized controlled trial

Randomized controlled trial

Randomized controlled

Randomized controlled trial

Crossover experiment

Randomized controlled trial

Randomized controlled trial
Single-blind (subjects)

Double-blind

$$
\text { age: 26.4) }
$$

124 subjects (age range: 18-59; mean age: 39.4 \pm 9.8 ) with seasonal affective disorder

18 normal, healthy employees working in one of two rooms, whereby room 1 had windows providing air ventilation and room 2 was mechanically ventilated

Phase I. No Blinding 8 manic patients (age range: 22-49)

Phase I: 4 Phase II: 4 Phase 4 Phase ll: 4

Low-density negative ion group: 13 Highdensity negative ion group: 12

13

124 (20 randomized to high-density negative ionization and 19 randomized to low-density negative ionization)

Double-blind

12 female undergraduates (age range: 18-22)

44 patients randomized to the control and 51 patients randomized to receive treatment (mean age among men: $37 \pm 18$; mean age among women: $43 \pm 20$ )

Double-blind

32 patients (age range: $22-65$; mean age: $43.7 \pm$ 12.4) with non-seasonal chronic depression

Single-blind (subjects) 118 mildly depressed and non-depressed college students (mean age: $19.4 \pm 1.7$ )

Double-blind

99 adults with seasonal depression (94 cases) and bipolar II disorder (five cases) (age range: 19-63; mean age: $40.4 \pm 10.4$

Double-blind

24 manic male patients (age range: $23-29$ mean age: 26.7)

Single-blind (subjects) 30 healthy subjects (age range: 18-28) randomized to either receive high-density negative air ion exposure or to a control condition

Single-blind (subjects) 73 university-affiliated women (age range: 18-51; mean age: $20.8 \pm 5.69$ ) with seasonal affective disorder
32 (22 randomized to low- or high-density) 118 (59 randomized to low or high density)

99 (39 randomized to low or high density)

24 (20 analyzed)

30 low or high density)
73 (38 randomized to 
Table 1 Study characteristics (Continued)

Malik et al., 2010[9] ${ }^{\text {a }} \quad$ Evaluate effect of negative ions on psychological stress

Dauphinais et al.,

2012[24]

Evaluate the effect of negative air ions on

seasonal depression

Harmer et al., 2012[31] Evaluate the effect of high-density negative air ions on emotional processing in patients with seasonal depression
Crossover experiment

Single-blind (subjects)

20 regular users of computers as part of their

Randomized controlled

Double-blind

Randomized controlled

Double-blind trial job (age range: 24-35: mean age: 28.9 )

44 adult patients (20 in the low-density group) 20

with bipolar depression

21 adult patients with seasonal depression;

21 controls. Mean ages of groups between

${ }^{\mathrm{a} A c t i v a t i o n}$, anxiety, mood.

${ }^{\mathrm{b}}$ Relaxation and sleep.

'Personal comfort rating.

${ }^{\mathrm{d}}$ Depression. 
$(n=24)$; one examined positive air ionization only; and eight studied the effects of both. Blinding of study subjects was not reported in three experiments, nor was it obvious upon review of the study methodology. Among the 30 studies that conducted blind experiments, 18 were double-blind. All but one study [19] was published in a peer-reviewed journal.

Air ion intensities and duration are summarized in Table 2. Air ion intensities were reported in 29 studies (range: 1000 ions $/ \mathrm{cm}^{3}$ (ambient levels) to 27,500,000 ions $/ \mathrm{cm}^{3}$ ). Air ionization duration ranged from 10 minutes at a single time point, to daily treatment periods administered for multiple days, to successive weeks at a time where air ion generators were switched on continuously. Collectively, many studies reported a mood-related response after exposure to ionized air; however, considerable variation by outcome, statistical significance testing, and degree of precision across the reported data was noted.

For reporting purposes, we have organized our review of studies by outcome, ascending year of publication, and the first author's last name.

\section{Activation, anxiety, and mood outcomes}

Four studies examined the effects of negative and positive air ions on activation, anxiety, and mood [15,16,25,27]. Silverman and Kornbleuh [27] conducted an experiment to examine the effect of negative and positive air ionization on the human electroencephalogram (blinding not reported). Ten healthy adults and two subjects with chronic stationary neurologic conditions participated in the study. Findings indicated a consistent decrease in alpha activity, a non-specific response, ranging from 0.5 to 1.5 cycle decrements during negative or positive air ionization, or both, in 10 subjects ( 9 healthy; 1 neurologically impaired).

Charry and Hawkinshire [15] examined the effect of positive air ions on mood in 85 subjects (age range: 18-60; mean age: 30 ) in contrast to ambient conditions in a singleblind experiment and found significantly greater tension and irritability in subjects' mood states. In particular, 'ion-sensitive' subjects showed that activation decreased and reaction times increased during exposure to positive air ions while non-sensitive subjects showed increased activation and no effects on reaction time.

Dantzler et al. [25] reported that ratings of mood on three questionnaires by nine subjects with bronchial asthma (age range: 35-64) were unaffected by exposure to negative and positive ions for 6-hour exposure periods in a double-blind crossover study. In contrast, Gianinni et al. [16] used a double-blind crossover design to evaluate the influence of negative and positive air ions in 14 university-affiliated volunteers and found that positive air ionization significantly increased anxiety, excitement, and suspicion. In contrast, negative air ionization significantly lowered subjects' extent of suspicion and excitement to those levels attained prior to positive air ion exposure.

Fifteen studies on activation, anxiety, and mood examined the effects of negative air ions only $[5,9,10,12,14,18,26,28-35]$. Tom et al. [34] utilized a double-blind randomized controlled study to determine the impact of negative air ions on mood in 56 adults (age range: 17-61; mean age: 23). No significant differences were observed between experimental and control conditions. On the other hand, Buckalew and Rizzuto [12] conducted a double-blind randomized controlled trial (RCT) and identified a significant improvement in mood attributed to negative air ionization between experimental ( $n=12$ men) and control ( $n=12$ men) groups (age range: $20-30$; mean age: 22.8 ).

Baron et al. [28] examined the effect of negative air ionization on mood, memory, and aggression as mediated by personality type among 71 male undergraduate students in a single-blind experiment. The authors found that exposure to moderate/high concentrations of negative air ions significantly heightened aggression among subjects classified as Type A, but not Type B. In addition, the authors reported that negative air ionization produced positive shifts in mood when not provoked by an accomplice, but negative shifts in mood when incited.

Deleanu and Stamatiu [29] conducted an experiment of 112 patients with mental disorders (blinding not reported). The overall study goal was to mitigate patients' symptoms by exposing them to negative aeroionotherapy for 10 to 30 days. The findings suggested that in the majority of treated patients, attenuation or the complete disappearance of anxiety and depressive reactions, including insomnia and general disposition, were identified. In contrast, Hedge and Collis [18] examined the impact of negative air ionization on mood in a double-blind study conducted among 28 healthy women and found no significant benefit of exposure.

Misiaszek et al. [14] explored the influence of negative air ions on eight manic patients (age range: 22-49) in an experimental pilot study conducted in two phases of four subjects each. The first phase was non-blind and the second was double-blind involving collection of data using anxiety and psychiatric metrics. In phase two, three of the four subjects showed score reductions consistent with clinical improvement; however, inference of these findings was impossible due to the limited number of subjects examined. A more recent single-blind experiment by Reilly and Stevenson [33] evaluated anxiety levels among eight healthy men (age range: 19-25) who were exposed to negative air ionization. The results showed no significant effect of air ions on state anxiety pre- or post-exercise [33]. In a single-blind study conducted by Watanabe et al. [35], 13 healthy adults (age 
Table 2 Air ion exposure assessment, psychological measures, and study findings

\section{Author and year}

Silverman and

Kornblueh 1957[27]

Negative air ion (30 minutes)

Positive air ion (30 minutes)

McGurk, 1959[17]

Negative air ion (5 hours)

$8.0 \times 10^{3} \mathrm{ions} / \mathrm{cm}^{3}$

Positive air ion (2 hours)

Yaglou, 1961[19] $]^{\text {b }} \quad$ Negative air ion (1-2 hours)

Positive air ion (1-2 hours)

Yaglou, 1961[19]

Negative air ion (1-2 hours)

Positive air ion (1-2 hours)

$10^{5}-10^{6} \mathrm{ions} / \mathrm{cm}^{3}$ air

5,000 to 10,000

ions $/ \mathrm{cm}^{3}$ air

Self-reported impressions (indifference, relaxation, air

Assael et al., 1974[11 $]^{\text {b }} \quad$ Negative air ion (45 minutes)

$3.5 \times 10^{5} \mathrm{ions} / \mathrm{cm}^{3}$

Albrechtsen et al., $1978[37]^{\mathrm{b}, \mathrm{c}}$ freshness, headache, respiratory irritation, restlessness)

Human electroencephalogram

Activations by hyperventilation, apnea, photic stimulation and sleep (natural)

Self-reported feelings of comfort, ease by which subjects worked on a cognitive task, and reactions to the test room atmosphere

incidencely, positive air ions seemed to increase the while negative air ions had little or no effect on the quality of air.

$5 \%$ of subjects reported feeling relaxed when exposed to positive air ions; $17 \%$ reported feeling relaxed when exposed to negative air ions; and $21 \%$ of subjects reported feeling relaxed under control conditions

Subjectively, negative air ions did not alleviate joint symptoms, while positive air ions seemed to make the symptoms worse; a higher frequency of patients reported feeling relaxed or sleepy, or both when exposed to negative versus positive air ions

Decrease in alpha frequency manifestation of general relaxation induced by negative air ions. Increase of amplitude interpreted as improvement of perception and apperception. Subjectively, all patients experienced initial relaxation followed by alertness connected with moving of alpha-waves from occipital to frontal areas.

spreading of alpha waves area

synchronization of right and left hemispheres Self-reported relaxation, alertness, working capacity, relief

No significant effects of positive or negative air ions found.
Negative air ion (Experiment

I: 8 hours; Experiment II: 15

minutes) Positive air ion

(Experiment l: 8 hours;

Experiment II: 15 minutes) Mental performance:

number of tasks per hour

$300-9,000 \mathrm{ions} / \mathrm{cm}^{3}$

Subjective voting based on \% scale:

extent of exertion

perception on air quality

perception of tasks

current feeling (sleepy vs. alert) 
Table 2 Air ion exposure assessment, psychological measures, and study findings (Continued)

Charry and Positive air ion (1.5 hours)

Hawkinshire, $1981[15]^{a}$ Ambient condition (contained both) (1.5 hours)

Hawkins, $1981[38]^{\text {b, c }} \quad$ Negative air ion (Weeks 5 to 12- on continuously)

Positive air ion (Weeks 5 to 12- on continuously)

Tom et al., 1981[34] $]^{\mathrm{a}, \mathrm{b}} \quad$ Negative air ion (15 minutes)

\section{Negative air ion \\ Control (natura environment):}

Buckalew and Rizzuto, Negative air ion (6 hours) 1982[12] $]^{\mathrm{a}, \mathrm{b}}$

Dantzler et al.

1983[25]

Negative air ion ( 6 hours)

Positive air ion (6 hours)

Baron et al., 1985[28] $]^{\mathrm{a}} \quad$ Negative air ion (20 minutes)

(dis

Stamatiu, 1985[29] a,b,d (daily treatment of 15-50

minutes for 10-30 days)

Gianinni et al.

1986[16]

Negative air ion (20 minutes)

Positive air ion (20 minutes)

reported

Positive air io

$2.9 \times 10^{3}$ ions $/ \mathrm{cm}^{3}$

Gianinni et al., Positive air ion (2 hours)

2,050-2,300 ions $/ \mathrm{cm}^{3} \quad$ Brief Psychiatric Rating Scale

\section{Brief Psychiatric Rating Scale} $204.4 \mathrm{ions} / \mathrm{cm}^{3}$

Likert scale survey for psychological state (difficulty of concentration, energetic, mood state, sociable, relaxed)

Taylor Manifest Anxiety Scale (TMAS)

Self-report Mood Index

Negative and positive Sharav Questionnaires 1 and 2 Mood Adjective Check List air ions: $60,000-$

10,000 ions $/ \mathrm{cm}^{3}$

20-3.0 $\times 10^{2}$ ions $/ \mathrm{cm}^{3}$

Moderate condition: $4 \times 10^{4} \mathrm{ions} / \mathrm{cm}^{3}$

High condition: 7.0-8.0 $\times 10^{4}$ ions $/ \mathrm{cm}^{3}$

Aggression measured by mean level of heat selected by subjects on each of the 20 occasions when the red light appeared

Memory measured by the number of traits and the accomplice

$1-1.5 \times 10^{4} \mathrm{ions} / \mathrm{cm}^{3} \quad$ Amelioration of asthenia, depressive reactions, anxiety, excitability and irascibility, cephalea, insomnia, and genera disposition in patients with various psychiatric disorders
For most subjects, mood changes induced by air ion

exposure characterized by increased tension and irritability.

Negative air ion exposure associated with higher subjective ratings of alertness, atmospheric freshness, environmental/personal warmth, and a reduction in the overall complaint rate by $50 \%$. Night-shift working was associated with discomfort and ill-health. Positive air ion effects were not explicitly discussed.

Subjects reported being more energetic and finding it easier to concentrate under the experimental condition than the control condition. Negative air ion exposure had a positive effect on certain aspects of human performance and mood.

Mood index data showed significant changes in the subjective perception of both physiological state (relaxation increased) and psychological state (irritability, depression, and tenseness decreased while calmness and stimulation increased).

Patients' mood did not differ significantly between the two ion exposures.

Exposure to moderate or high levels of negative air ions significantly enhanced aggression by Type A subjects, but not among others. Negative air ions produced positive shifts in reported moods in the absence of provocation but negative shifts in moods in the presence of provocation.

In most treated patients, a diminution or even the disappearance of the target symptoms was obtained (asthenia, depressive reactions, anxiety, irascibility, cephalea, insomnia, and general disposition).

Cations were found to increase anxiety, excitement, and suspicion. Anions reversed the effects of cations and, in addition, reduced suspicion and excitement to levels below those occurring before cationization.

Symptoms of anxiety and excitement significantly increased. During the time of exposure, serum serotonin levels also increased significantly.

2,050-2,300 ions/em Prief Psyiatric Rating Scale


\begin{tabular}{l} 
Table 2 Air ion exposure assessment, psychological measures, and study findings (Continued) \\
\hline Finnegan et al., Negative air ion (6-8 weeks) $\quad 1.84 \times 10^{3}$ ions $/ \mathrm{cm}^{3} \quad$ Personal comfort rating
\end{tabular}

1987[40]

Hedge and Collis,

$1987[18]^{\mathrm{a}}$

Lips et al., 1987[13] $]^{\text {b,c }} \quad$ Negative air ion Weeks 2 and 4 - on continuously; Week 3 mornings only

Misiaszek et al. $1987[14]^{\mathrm{a}, \mathrm{b}}$

Negative air ion Phase l: hour: Phase II: 1.5 hours

Reilly and Stevenson, 1993[33]

Negative air ion (30 minutes pre-test +40 minutes during test)

Terman and Terman, Negative air ion (30 minute $1995[6]^{\mathrm{d}}$ sessions for 20 days)

Watanabe et al., $1997[35]^{a, c}$

Terman et al. $1998[8]^{b, c}$

Negative air ion (30 minutes per day for 10-14 days)
$2 \times 10^{4} \mathrm{ions} / \mathrm{cm}^{3}$

Mood Adjective Check List

Two cognitive tasks:

naming 24 different colors printed on card

Stroop Colour Word test

$5 \times 10^{4}$ ions $/ \mathrm{cm}^{3}$

10 linear scales (rated 0 to 10) on which each subject was asked to assess his or her well-being and the quality of the environment

Phase I: 40,000-60,000 State Trait Anxiety Inventory and Inpatient

small,

Multidimensional Psychiatric Scale

50-1000 medium

$50-4,000$ large ions/

$\mathrm{cm}^{3}$

Phase II: 50,000-70,000

small,

50-3,200 medium,

$50-7,000$ large ions/

$\mathrm{cm}^{3}$

$1.72 \times 10^{5} \mathrm{ions} / \mathrm{cm}^{3}$

Low density:

$1.0 \times 10^{4} \mathrm{ions} / \mathrm{cm}^{3}$

High density:

$27 \times 10^{6} \mathrm{ions} / \mathrm{cm}^{3}$

Negative air ion (10 minutes) $2.0 \times 10^{4} \mathrm{ions} / \mathrm{cm}^{3}$

Low density:

$1.0 \times 10^{4}$ ions/

$\mathrm{cm}^{3}$ High density:

$2.7 \times 10^{6} \mathrm{ions} / \mathrm{cm}^{3}$
Measurements were made of state anxiety according to Spielberger et al. (1970)

SIGH - SAD

Clinical Global Impressions Scale and sweating

SIGH - SADSelf-rating version of the SIGH-SADSleep patterns

No significant effect on personal comfort found. Effects on symptoms were non-significant except for URTI and nausea in the high negative air ion period.

Evidence for beneficial effects of negative air ions on mood and performance could not be demonstrated.

After their exposure to enhanced negative air-ion concentrations, the subjects' assessments of both their own well-being and the quality of the environment improved significantly: neither harmful effects of exposure to enhanced levels of negative air ions nor changes in perceived thermal comfort were detected.

Phase I: All subjects fell to sleep, reported being calm afterwards; manic behavior reappeared 5-10 minutes after treatment

Phase II: 3/4 subjects fell to sleep, 1 subject appeared less agitated; manic behavior reappeared 5-10 minutes after treatment

There was no significant effect of air ions on state anxiety pre-or post-exercise or on the perception of effort.

The severity of depressive symptoms decreased selectively for the group receiving high-density treatment. When a remission criterion of $50 \%$ or greater reduction in symptom frequency/severity was used, $58 \%$ of subjects responded to high-density treatment while 15\% responded to low-density treatment.

There were no differences in the moods of these persons or changes in their blood pressures between the two saunas.

mproved depression rating of $42-50 \%$ and $20-40 \%$ remission rate. Described as a "small effect" in period 1 and "large effect" in period 2. Analysis of depression scale percentage change scores showed low-density air ion response to be inferior to all other groups, with no other group differences. Sleep measures subjects given morning light awakened $0.62 \pm 0.62$ hours earlier than at baseline: negative air ions, $0.41 \pm 0.37$ hours earlier; and evening light, $0.09 \pm 0.58$ hours earlier. 


\begin{tabular}{llrl}
\hline $\begin{array}{l}\text { Nakane et al., } \\
2002[10]^{\mathrm{a}}\end{array}$ & $\begin{array}{l}\text { Negative air ion }(40 \text { minutes } \\
\text { during task or } 30 \text { minutes } \\
\text { post-task) }\end{array}$ & $5.5-7.3 \times 10^{3} \mathrm{ions} / \mathrm{cm}^{3}$ & $\begin{array}{l}\text { Japanese version of the State-Trait Anxiety Inventory, } \\
\text { Anxiety StateSalivary cortisol and chromogranin A-like }\end{array}$ \\
immunoreactivityTask performance
\end{tabular}

immunoreactivityTask performance

Iwama et al.,
2004a[39]
Goel et al., 2005[22] $]^{\text {b,d }}$
Goel and Etwaroo,
2006[5] $]^{\text {a,b,d }}$

Terman and Terman, Negative ion (93 minutes $2006[7]^{b, d}$

Gianinni et al.,

2007[26]

Malcolm et al., $2009[32]^{a, b}$

Negative ion (not reported) 3000 parts $/ \mathrm{cm}^{3 f}$

Negative ion (1 hour upon wakening for 5 weeks)

Negative ion (30 minutes for three consecutive evenings)

Negative ion (1 hour)

Negative ion (30 minutes

pre-test and 60 minutes

during test)

Low density:

High density:

Low density:

$4.5 \times 10^{14}$ ions $/ \mathrm{sm}^{3}$

Low density:

High density:

Not reported
Degree of tension: 1 = relaxed; 2 = normal tension;

$3=$ mild tension; 4 = moderate tension; and

$5=$ severe tension

$1.7 \times 10^{11} \mathrm{ions} / \mathrm{s}$
$\left[1 \times 10^{4} \mathrm{ions} / \mathrm{cm}^{3}\right]^{\mathrm{e}}$

$4.5 \times 10^{14} \mathrm{ions} / \mathrm{s}$

$\left[2.7 \times 10^{7} \mathrm{ions} / \mathrm{cm}^{3}\right]^{e}$

$1.7 \times 10^{11} \mathrm{ions} / \mathrm{s}$

$\left[1 \times 10^{4} \mathrm{ions} / \mathrm{cm}^{3}\right]$
eHigh density:

$\left[2.7 \times 10^{7} \mathrm{ions} / \mathrm{cm}^{3}\right]^{\mathrm{e}}$

The Profile of Mood

States Questionnaire

The Karolinska Sleepiness Scale

Likert scales assessed four aspects of stimulus perception using a 7-point scale. Subjects rated stimulus hedonics and intensity, as well as its effects on mood and on alertness

$1.7 \times 10^{11} \mathrm{ions} / \mathrm{s}$

$\left[1 \times 10^{4} \mathrm{ions} / \mathrm{cm}^{3}\right]^{\mathrm{e}}$

$4.5 \times 10^{14} \mathrm{ions} / \mathrm{s}$

$\left[2.7 \times 10^{7} \mathrm{ions} / \mathrm{cm}^{3}\right]^{\mathrm{e}}$

$3 \times 10^{3}$ ions $/ \mathrm{cm}^{3}$

Brief Psychiatric Rating Scale

Subjective state measured by six visual analogue scales for happiness, sadness, hostility, alertness, anxiety and

calmness.

The emotional test battery consisted of an emotional categorization task with surprise emotional recall and

recognition, a facial expression recognition test, and a dotprobe task of attention with masked and unmasked conditions.
The increase in the CgA-like IR level was attenuated by the exposure to negative air ions during the task. The

exposure to air ions during the recovery period following the task was effective for rapidly decreasing the CgA-like IR level that had increased after the task. These effects by IR level that had increased after the task. These effects by
negative air ions were also observed using STAI-S. Task performance was slightly but significantly improved by the presence of negative air ions.

Degree of tension decreased significantly and more rapidly in the negative ion-rich environment.

SIGH-SAD score improvement was $51.1 \%$ for high-density ions v. $17.0 \%$ for low-density ions. Remission rates were $50 \%$ and $0 \%$, respectively.

The three active stimuli (bright light, auditory stimuli, or high-density negative ion exposure), but not the lowdensity placebo, reduced depression, total mood disturbance and/or anger within 15-30 min.

Post-treatment improvement results were high-density ions, 47.9\%; and low-density ions, 22.7\% (significantly different).

A significant anti-manic effect was observed: total rating scores declined with anion treatment.

Association between BDI score and treatment; increased recall and recognition of positive terms versus negative terms; findings indicate that HDNI treatment produces a positive bias in emotional recall and recognition. 
Table 2 Air ion exposure assessment, psychological measures, and study findings (Continued)

\begin{tabular}{|c|c|c|c|c|}
\hline \multirow[t]{3}{*}{ Flory et al., 2010[4] ${ }^{d}$} & \multirow[t]{3}{*}{$\begin{array}{l}\text { Negative ion ( } 30 \text { minutes for } \\
12 \text { days) }\end{array}$} & $\begin{array}{l}\text { Low density: } \\
4.0 \times 10^{3} \text { ions } / \mathrm{cm}^{3}\end{array}$ & SIGH - SAD-Self Rating: & \multirow{3}{*}{$\begin{array}{l}\text { Subjects in all four groups showed significant score } \\
\text { decreases on the SIGH-SAD-SR and on the BDI. For raw } \\
\text { scale scores, neither main effects of treatment nor } \\
\text { interactions between treatment and time were significant. } \\
\text { When remission outcome criteria were used, exposure to } \\
\text { high-density negative ions was more effective than either } \\
\text { of the two placebo conditions, although the difference } \\
\text { was not significant. }\end{array}$} \\
\hline & & \multirow{2}{*}{$\begin{array}{l}\text { High density: } \\
\geq 2.0 \times 10^{6} \text { ions } / \mathrm{cm}^{3}\end{array}$} & $\mathrm{BDI}$ & \\
\hline & & & $\begin{array}{l}\text { Diagnostic and Statistical Manual of Mental Disorders } \\
\text { (DSM-IV) criteria for SAD }\end{array}$ & \\
\hline Malik et al., 2010[9] & Negative ion (2 hours) & $\begin{array}{l}>1,000,000 \text { counts/ } \\
\mathrm{cm}^{3}\end{array}$ & $\begin{array}{l}\text { Self-reported computer-oriented stress, physiological and } \\
\text { psychological stress }\end{array}$ & $\begin{array}{l}\text { A significant decline in computer-oriented stress and } \\
\text { psychological stress was noticed post-computer } \\
\text { operations in presence of negative ions. }\end{array}$ \\
\hline $\begin{array}{l}\text { Dauphinais et al., } \\
2012[24]^{d}\end{array}$ & $\begin{array}{l}\text { Negative ion }(7.5 \mathrm{~min} / \text { day or } \\
15 \mathrm{~min} / \text { day if tolerable for } 8 \\
\text { weeks) }\end{array}$ & $\begin{array}{l}1.7 \times 10^{11} \mathrm{ions} / \mathrm{s} \\
{\left[1 \times 10^{4} \mathrm{ions} / \mathrm{cm}^{3}\right]^{\mathrm{e}}}\end{array}$ & SIGH-SAD & $\begin{array}{l}\text { No significant difference in SIGH-SAD scores between } \\
\text { light therapy and low-density negative ion groups at } \\
\text { study end or in the proportions of responders or remitters } \\
\text { in these groups. }\end{array}$ \\
\hline \multirow[t]{2}{*}{$\begin{array}{l}\text { Harmer et al., } \\
2012[31]^{\mathrm{a}, \mathrm{b}, \mathrm{d}}\end{array}$} & \multirow[t]{2}{*}{$\begin{array}{l}\text { Negative ion ( } 30 \text { minutes } \\
\text { pre-test and } 60 \text { minutes } \\
\text { during test) }\end{array}$} & \multirow[t]{2}{*}{ Not reported } & $\begin{array}{l}\text { Subjective state measured by six visual analogue scales } \\
\text { (happiness, surprise, sadness, fear, anger, and disgust), BDI, } \\
\text { and State-Trait Inventory }\end{array}$ & \multirow{2}{*}{$\begin{array}{l}\text { No effect on anxiety, depression (BDI), alertness, and recall } \\
\text { of emotional words. HDNI treatment decreased } \\
\text { recognition of faces showing disgust and increased } \\
\text { recognition of happy faces, and increased recognition of } \\
\text { and vigilance to positive words. HDNI increased } \\
\text { recognition memory of positive words only in the SAD } \\
\text { group. The findings indicate that HDNI treatment } \\
\text { produces a positive bias in emotional recall and } \\
\text { recognition. }\end{array}$} \\
\hline & & & $\begin{array}{l}\text { The emotional test battery consisted of an emotional } \\
\text { categorization task with surprise emotional recall and } \\
\text { recognition, a facial expression recognition test, and a dot- } \\
\text { probe task of attention with masked and unmasked } \\
\text { conditions. }\end{array}$ & \\
\hline
\end{tabular}

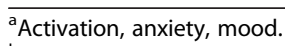

${ }^{\mathrm{b}}$ Relaxation and sleep.

cPersonal comfort rating.

dDepression.

e ens $/ \mathrm{s}$ converted to ions $/ \mathrm{cm}^{3}$ for ionizers used in this laboratory based on Terman et al. [8].

fon concentration in ion $/ \mathrm{cm}^{3}$ based upon Iwama et al. [41]

$B D I$ beck depression inventory; CgA-like IR chromogranin A-like immunoreacitivity; HDNI high-density negative ions; SR self-rating; STAl-S state trait anxiety inventory scale; SIGH-SAD structured interview guide for the hamilton depression rating scale, seasonal affective disorder. 
range: 21-49; mean age: 26.4) rated their mood after entering a sauna system on two occasions-one with negative air ionization, the other without. The authors observed no significant difference in reported mood states between experimental and control conditions.

Nakane et al. [10] conducted a crossover study (blinding not reported) among 12 female undergraduates (age range: 18-22) to examine the effect of negative air ionization on anxiety and salivary chromogranin A-like immunoreactivity (CgA-like IR), a protein indicator of sympathetic nerve activity. The findings showed that exposure to negative air ions significantly reduced anxiety compared to the positive control while performing a computer-oriented task, but negative air ionization in the post-task period was associated with a non-significant reduction. Similar results were reported for CgA-like IR.

Goel and Etwaroo [5] performed a single-blind RCT to determine the immediate effects of bright light, auditory stimulus, and high-density $(\mathrm{n}=29)$ and low-density negative air ionization $(n=30)$ on mood and attentiveness in 118 mildly depressed and non-depressed college students (mean age: 19.4). The results showed that exposure to high-density negative air ionization decreased depressive symptoms, total mood disturbance, or anger within 15 to 30 minutes of exposure; however, low-density exposure did not produce significant effects.

A double-blind crossover experiment by Gianinni et al. [26] exposed 24 manic men (age range: 23-29; mean age: 26.7) to high levels of ambient negative air ions and found a statistically significant reduction in subjects' manic states. In contrast, Malcolm et al. [32] conducted a single-blind experiment among 30 healthy subjects (age range: 18-28) randomized to receive either high-density negative air ions or a control condition and found no effect of exposure on anxiety. Of note, the clinic that performed the Malcolm et al. [32] study subsequently performed a double-blind RCT of adults (21 patients with SAD and 21 controls) exposed to high-density negative air ions and also reported no effect on measures of visual analogue (mood) or StateTrait Anxiety Inventory ratings [31]. When Malik et al. [9] induced stress in 20 adults (age range: 24-35; mean age: 28.9) in a single-blind study by performing a computer-oriented task, the subjects reported a significant decrease in computer-oriented stress and psychological stress following negative air ionization.

Gianinni et al. [36] researched the effects of positive air ions only in a double-blind crossover study conducted among 12 adult male volunteers and found that anxiety, excitement, and serum serotonin levels significantly increased when exposed.

\section{Relaxation and sleep}

Several studies examined the impact of negative and positive air ionization on relaxation and sleepiness. In the study by Silverman and Kornbleuh [27], more than half of their 12 subjects reported one or more symptoms of dryness of the mouth/upper respiratory tract, relaxation, or sleepiness when exposed to either negative or positive air ionization; however, these responses were more prevalent during negative air ionization. Yaglou [19] conducted a single-blind crossover study in 25 healthy adults (age range: 22-51) and a separate study in 6 arthritic patients (age range: $30-62$ ) to examine the effects of negative and positive air ionization on relaxation. In the first study of 25 adults, 5\% reported feeling relaxed when exposed to positive air ions; $17 \%$ reported feeling relaxed when exposed to negative air ions; and $21 \%$ reported feeling relaxed under control conditions [19]. In the second study, a higher frequency of patients reported feeling relaxed or sleepy, or both, when exposed to negative versus positive air ions [19].

Albrechtsen et al. [37] conducted two single-blind experiments to evaluate the influence of negative and positive air ionization on subjective feelings among two groups: 6 randomly-selected women (age range: 20-30) and 12 adults (age range: 19-45) who appeared to be most sensitive to ionization. Outcomes included subjective assessments on feelings of self-exertion, stuffiness, the unpleasantness of cognitive tasks performed, and sleepiness. Across both studies, no significant effects were identified. Hawkins [38] examined the influence of negative and positive air ionization in an office environment on personal ratings of thermal comfort, stuffiness, alertness, and well-being in a double-blind crossover experiment conducted over 12 weeks. Subjects $(n=106)$ were divided into groups based on areas of variable ionization levels. Hawkins observed that negative air ionization was associated with higher subjective ratings of alertness, atmospheric freshness, environmental/personal warmth, and a reduction in the overall complaint rate by $50 \%$. Positive air ion effects were not explicitly discussed.

Twelve studies examined the association of negative air ions only with relaxation and sleepiness [5,7,8,11-14,22,29,32,34,39]. Assael et al. [11] conducted a double-blind crossover study to examine the effects of negative air ions on relaxation and alertness among 10 healthy participants (age range: 20-65) and 10 subjects on tranquilizers. The authors found that all patients reported an initial relaxation followed by alertness when exposed to negative air ions.

Three previously mentioned studies on air ions and mood associations also evaluated ion effects on relaxation or sleepiness, or both $[12,29,34]$. The double-blind experiment conducted by Tom et al. [34] of 56 adults assessed the impact of negative air ions on relaxation (very tense versus very relaxed). Although reported feelings of relaxation were slightly elevated in the experimental compared to the control group, the findings were 
statistically non-significant. On the other hand, Buckalew and Rizzuto [12] identified a significant increase in relaxation attributed to negative air ionization between experimental and control groups in their double-blind study. In the work of Deleanu and Stamatiu [29], sleep normalization was achieved in 53 of 67 patients with insomnia who were exposed to negative air ions (blinding not reported).

Lips et al. [13] performed a double-blind crossover trial to examine the effect of negative air ions on alertness in 18 healthy adults. Subjects worked in either room one with windows (natural ventilation) or room two with no windows (mechanically ventilated). Lips et al. [13] observed that following exposure to enhanced negative air ions, subjects' feelings of drowsiness were significantly reduced within both rooms. In the pilot study by Misiaszek et al. [14], all four subjects fell asleep and reported feeling calm following negative air ionization in the first phase of the study (non-blind). In the second phase (double-blind), three of the four subjects fell asleep and one subject appeared less agitated. In both phases, patients' manic behavior reappeared 5 to 10 minutes post-treatment [14].

Terman et al. [8] conducted a double-blind crossover experiment to examine the effects of timed bright light and negative air ionization on sleep timing in 124 subjects (age range: 18-59; mean age: 39.4 ), with 20 subjects randomized to high-density and 19 subjects randomized to low-density negative air ionization. The findings showed that exposure to high-density versus low-density negative air ionization did not result in statistically significant differences in sleep patterns. On the other hand, Iwama et al. [39] conducted a double-blind experiment with 44 patients randomized to the control and 51 patients randomized to receive negative air ion treatment (mean age: 40). Five degrees of tension were defined: $1=$ relaxed; $2=$ normal tension; $3=$ mild tension; $4=$ moderate tension; and $5=$ severe tension. The authors found that treated patients' tension reduced significantly and quicker.

Goel et al. [22] conducted a double-blind RCT to evaluate the efficacy of bright light and high-density negative air ionization for non-seasonal chronic depression and sleep in 32 patients (age range: 22-65; mean age: 43.7). The findings showed no significant change in sleep onset between high-density $(\mathrm{n}=12)$ and low-density $(\mathrm{n}=10)$ negative air ionization; but a significant alteration in sleep offset was noted among the high-density subjects. Similarly, in a single-blind study of light and air ion treatment for depression, Goel and Etwaroo [5] found no significant differences in subjects' feelings of sedation, pleasantness, or intensity. In a double-blind RCT by Terman and Terman [7], 99 adults with SAD (age range: 19-63; mean age: 40.4) were followed to examine the effects of high- and low-density negative air ionization and light therapy during subjects' final hours of sleep. Sleep disturbances in 3 of 16 patients in the low-density group were observed, but none in the high-density group.

In a single-blind experiment of 30 healthy subjects (age range: 18-28) randomized either to receive high-density negative air ionization or to a control condition, Malcolm et al. [32] found no effect of air ionization on subjects' feelings of alertness or calmness. A subsequent doubleblind RCT of SAD patients and controls reported no effect on patient alertness and found that negative air ion treatment increased vigilance to unmasked positive items in the visual dot-probe task regardless of patient group [31].

\section{Personal comfort ratings}

Three studies evaluated the impact of negative and positive air ionization on personal comfort $[17,37,38]$. McGurk [17] examined the effects of negative and positive air ions on self-reported feelings of comfort, ease of working on cognitive tasks, and reactions to the test room environment in 10 college-aged males undergoing a single-blind experimental assessment. All subjects were informed that on some days the air would be ionized; however, subjects remained uninformed about polarity. The findings showed that negative air ion exposure resulted in a notable increase in the proportion of subjects reporting more pleasant feelings, while positive air ion exposure versus the control condition resulted in a significantly higher reporting of unpleasantness.

Findings in the Albrechtsen et al. [37] study found no significant relationship between exposure to high concentrations of negative and positive air ions and feelings of self-exertion, stuffiness, or the unpleasantness of cognitive tasks among 25 healthy subjects or 6 arthritic patients. In contrast, Hawkins [38] observed that negative air ion exposure was associated with higher subjective ratings of alertness, atmospheric freshness, and environmental/personal warmth among office employees working in three different areas of variable air ionization levels (double-blind study).

Several more recent studies $[13,35,40]$ examined the influence of exposure to negative air ions only on personal comfort among adults. Finnegan et al. [40] conducted a single-blind experiment and found no significant effect of negative air ionization on personal comfort among 26 adults working within 5 different rooms of an office building. On the other hand, Lips et al. [13] examined the effects of negative air ion exposure on personal comfort and well-being in a doubleblind study of 18 healthy adults who worked in either a room with windows (normal environment) or one mechanically ventilated (ion-depleted environment). The findings showed that following exposure to enhanced negative air ions, subjects' assessments of both their own 
well-being and their environments (room pleasantness and comfort) improved significantly at both sites, but failed to result in a significant difference in personal thermal comfort scores. In addition, subjects in the iondepleted environment failed to experience an improvement in air freshness during negative air ion exposure. In the single-blind, ion-enhanced sauna study by Watanabe et al. [35], no significant differences in the reported feelings of pleasantness between exposure settings were observed.

\section{Depression}

All depression studies evaluated potential alterations only from exposure to negative air ions [4-8,22,24,29,31]. In the study of 112 psychiatric patients by Deleanu and Stamatiu [29], the findings showed that in over $50 \%$ of 45 treated patients diagnosed with depression, depressive reactions attenuated or completely disappeared with exposure to negative air ions (blinding not reported). Terman and Terman [6] performed a double-blind RCT among 25 patients (mean age: 38.2 ) to examine the effects of negative air ions on SAD. Subjects were randomized to low-density $(n=13)$ or high-density $(n=12)$ treatment. The authors found that depression severity decreased (determined using SIGH-SAD) more notably for the high- than the low-density treatment group. Applying a remission criterion of $\geq 50 \%$ reduction in symptom severity, $58 \%$ of patients reacted to high-density and 15\% reacted to lowdensity air ion exposure. Terman et al.'s [8] double-blind study of the effects of timed bright light and negative air ionization on SAD in 124 adults showed that exposure to high-density air ionization provided subjects with clinically significant relief by producing a $50 \%$ reduction in depressive symptoms from baseline. In addition, the remission rate associated with high-density negative air ionization rose substantially with an additional 10 to 14 days of treatment after the first period, but low-density exposure showed no significant effect [8].

In their double-blind study evaluating the efficacy of bright light and high-density negative air ion exposure for non-seasonal chronic depression in 32 adults, Goel et al. [22] observed a score improvement on the SIGH-SAD of $51 \%$ for high-density exposure (remission rate $50 \%$ ) compared to $17 \%$ for low-density exposure (remission rate $0 \%$ ). Similarly, Goel and Etwaroo's [5] single-blind study of the immediate effects of bright light $(\mathrm{n}=29)$, auditory stimulus $(\mathrm{n}=30)$, high-density $(\mathrm{n}=29)$, and low-density negative air ionization $(\mathrm{n}=30)$ in mildly depressed and non-depressed adults indicated that exposure to high-density negative air ions decreased depressive symptoms within 15 to $30 \mathrm{~min}$ utes; however, low-density exposure did not produce any significant effects.

In a double-blind RCT by Terman and Terman [7], 99 adults with SAD or bipolar II disorder were followed to examine the effects of high- and low-density negative air ionization and light therapy during the final hours of sleep. Study findings based on SIGH-SAD indicated that exposure to low-density negative air ions resulted in a significantly lower improvement $(22.7 \%)$ in depression scores compared to improvement with high-density exposure (47.9\%). Flory et al. [4] also investigated the effects of high- and low-density negative air ionization and light therapy on SAD among 73 university-affiliated women (age range: 18-51; mean age: 20.8) in a singleblind RCT and found that subjects in all study groups showed significant score decreases on the SIGH-SAD self-rating scale and the Beck Depression Inventory (BDI) scale. Dauphinais et al. [24] performed a doubleblind RCT of adult patients with bipolar depression to examine the effect of negative air ions. Subjects were randomized to low-density $(n=20)$, high density $(n=2)$, or bright light $(n=18)$ treatment for 8 weeks. Of note, the low-density group was considered the control and too few data were available for the high-density group to allow for a meaningful analysis; therefore, data among the high-density group were not reported. The authors found no significant difference between the depression severity scores (determined using SIGH-SAD) of the light and low-density treatment groups $(52 \%$ vs. $47 \%$ reduction, respectively) or between the proportion of responders and remitters (light group-50\% of subjects were either responders or remitters; low density ion group $-55.6 \%$ of subjects in the low-density treatment group were either responders or remitters).

Harmer et al. [31] exposed $21 \mathrm{SAD}$ patients and 21 controls in a double-blind RCT to high levels of negative air ions for 1.5 hours. Post-exposure measures of depression, as measured by the BDI scale, were unaffected by treatment. Additionally, SAD patients, but not controls, exhibited an increased recognition memory for positive words. The overlap in the results of this study with those of Malcolm et al. [32], and parallels between air highdensity negative ion treatment and single-dose antidepressant administration on negative affective bias $[41,42]$, suggest a link between emotional processing of certain stimuli and depressive states.

\section{Meta-analysis of depression studies}

The forest plots and overall weighted differences in group means (i.e. pre- minus post-ion exposure mean scores) by ion concentration (high/low) are shown in Figures 1 and 2. Estimates of treatment effects for studies with multiple follow-up times [6-8] were examined by time point also. Utilizing the later post-baseline mean score where applicable, the weighted differences in group means for the Atypical symptom subscale, Hamilton subscale, and composite SIGH-SAD scale were 5.64 (95\% CI: 4.44-6.85), 9.23 (95\% CI: 8.52-9.94), and 14.28 (95\% CI: 


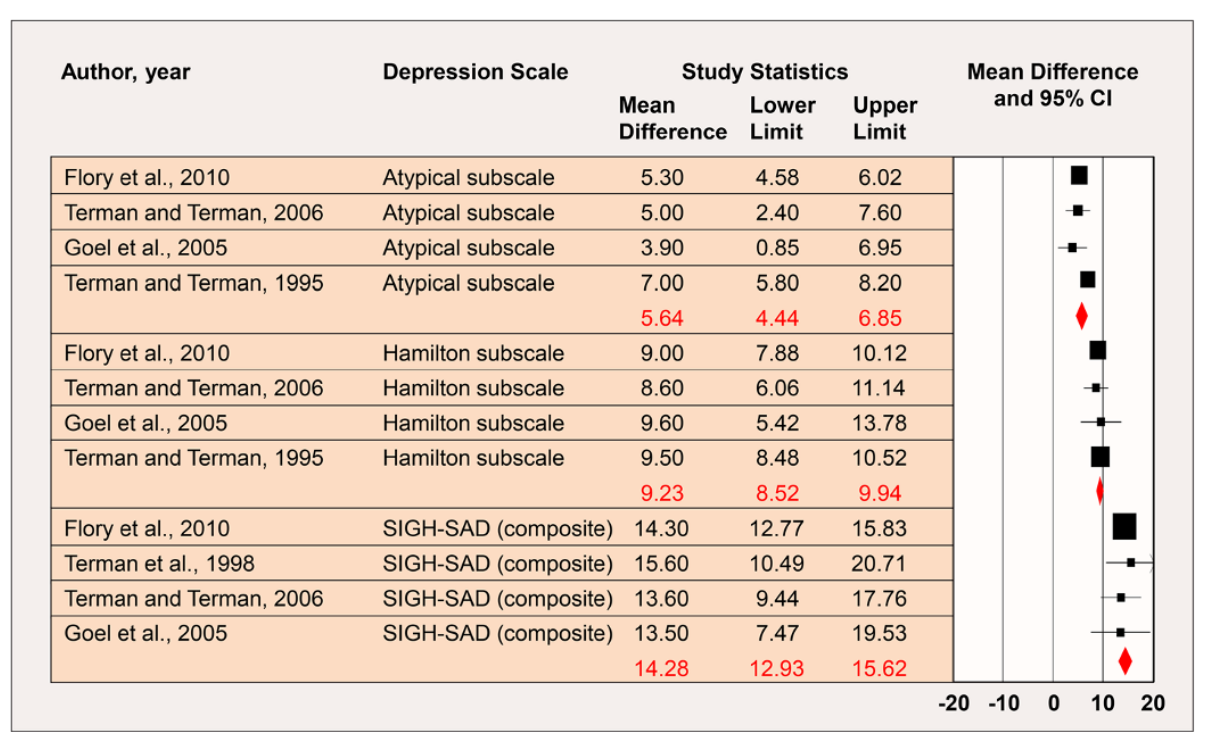

Figure 1 High-Density Negative Air Ion Exposure and Depression. ${ }^{*}$ Includes data from studies at the last follow-up time point where applicable [6-8]; $p$ for heterogeneity (composite SIGH-SAD) = 0.94. Cl: Confidence Interval; SIGH-SAD: Structured Interview Guide for the Hamilton Depression Rating Scale, Seasonal Affective Disorders.

12.93-15.62), respectively ( $p$ for heterogeneity (SIGH$\mathrm{SAD})=0.94$ ); thus, the results were indicative of a beneficial effect of high-density negative air ion treatment on SAD and treatment effects were comparable between studies (Figure 1). The weighted differences in group means in the low-density negative air ion analysis for the Atypical symptom subscale, Hamilton subscale, and composite SIGH-SAD scale were 1.98 (95\% CI: 0.57-3.40), 4.87 (95\% CI: $0.96-8.77)$, and 7.23 (95\% CI: $2.62-11.83$ ), respectively $(p$ for heterogeneity (SIGH-SAD) < 0.0001); thus the results were also statistically significant, but smaller in magnitude and were significantly different between studies (Figure 2).

The findings were similar when utilizing the earlier post-baseline mean score reported by Terman and Terman [6,7] and Terman et al. [8] (results not shown); however, the magnitude of effect by subscale and overall was consistently smaller than those shown in Figures 1 and 2. Furthermore, the weighted group mean difference for the Atypical symptom subscale was statistically non-

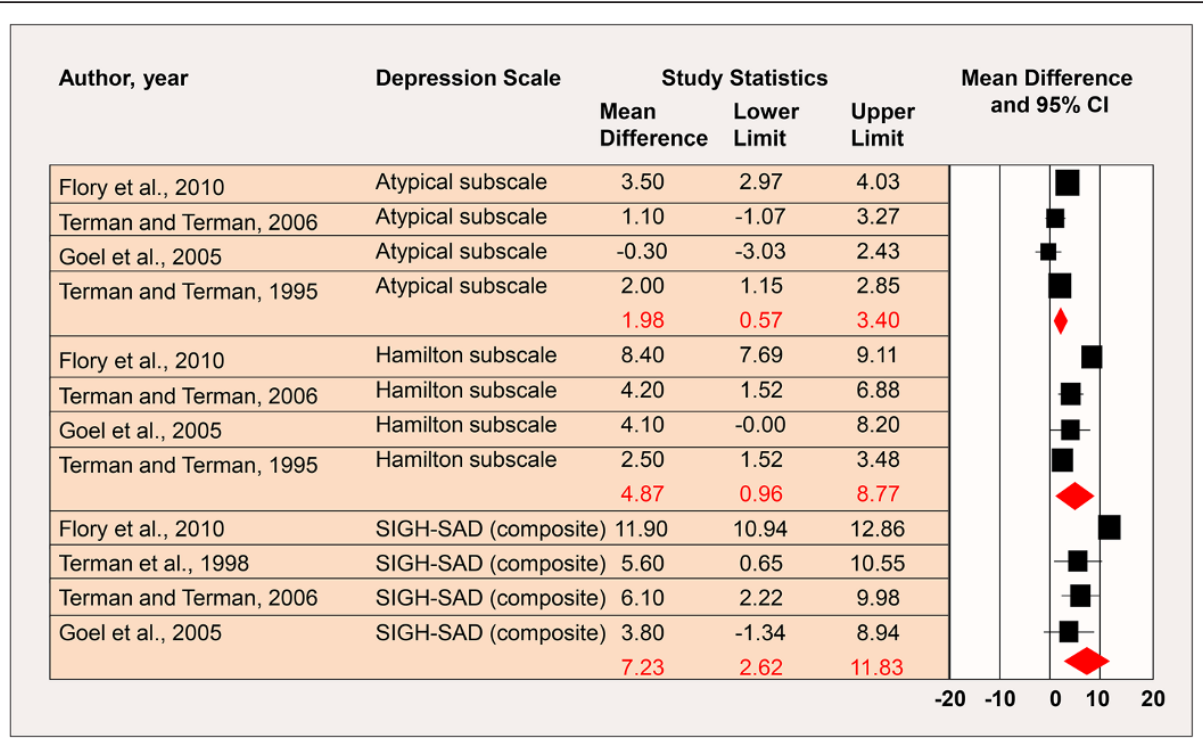

Figure 2 Low-Density Negative Air Ion Exposure and Depression. *Includes data from studies at the last follow-up time point where applicable [6-8]; $p$ for heterogeneity (composite SIGH-SAD) < 0.0001. Cl: Confidence Interval; SIGH-SAD: Structured Interview Guide for the Hamilton Depression Rating Scale, Seasonal Affective Disorders. 
significant in the low-density negative ionization analysis (mean=1.54 (95\% CI: -0.31-3.39)).

Sensitivity analyses were performed by removing the Terman and Terman [6] study since the data were presented in a figure and not explicitly reported. These analyses showed no alteration in the findings. An additional assessment of exposure duration (hours), within high- and low-density air ion levels, and each study's score mean difference indicated no evidence of a doseresponse relationship (Figure 3).

Publication bias was examined visually with funnel plots, which allow for a visual assessment of the estimated intervention effects from the individual studies plotted against a measure of treatment effect size. Separate plots were done for SIGH-SAD composite scores and SIGHSAD subscales combined since Terman and Terman [6] reported estimates by subscale only and Terman et al. [8] reported estimates for the composite scale only. A clustering indicative of publication bias was not observed (Figure 4) (i.e., no marked asymmetry was evident). Statistical evidence of publication bias was not found (Begg rank correlation $p=0.71$; Egger regression $p=0.37$ ). These findings were supported by those observed when combining the Atypical and Hamilton subscales.

\section{Discussion}

This review and meta-analysis examined the relationship between negative/positive air ion exposure and emotional state in 33 human experimental studies published from 1957 to August, 2012. To our knowledge, this is the first comprehensive review to summarize the literature on air ionization and psychological outcomes. Also, no studies have previously meta-analyzed the influence of high- and low-density negative air ions on subjects' depression
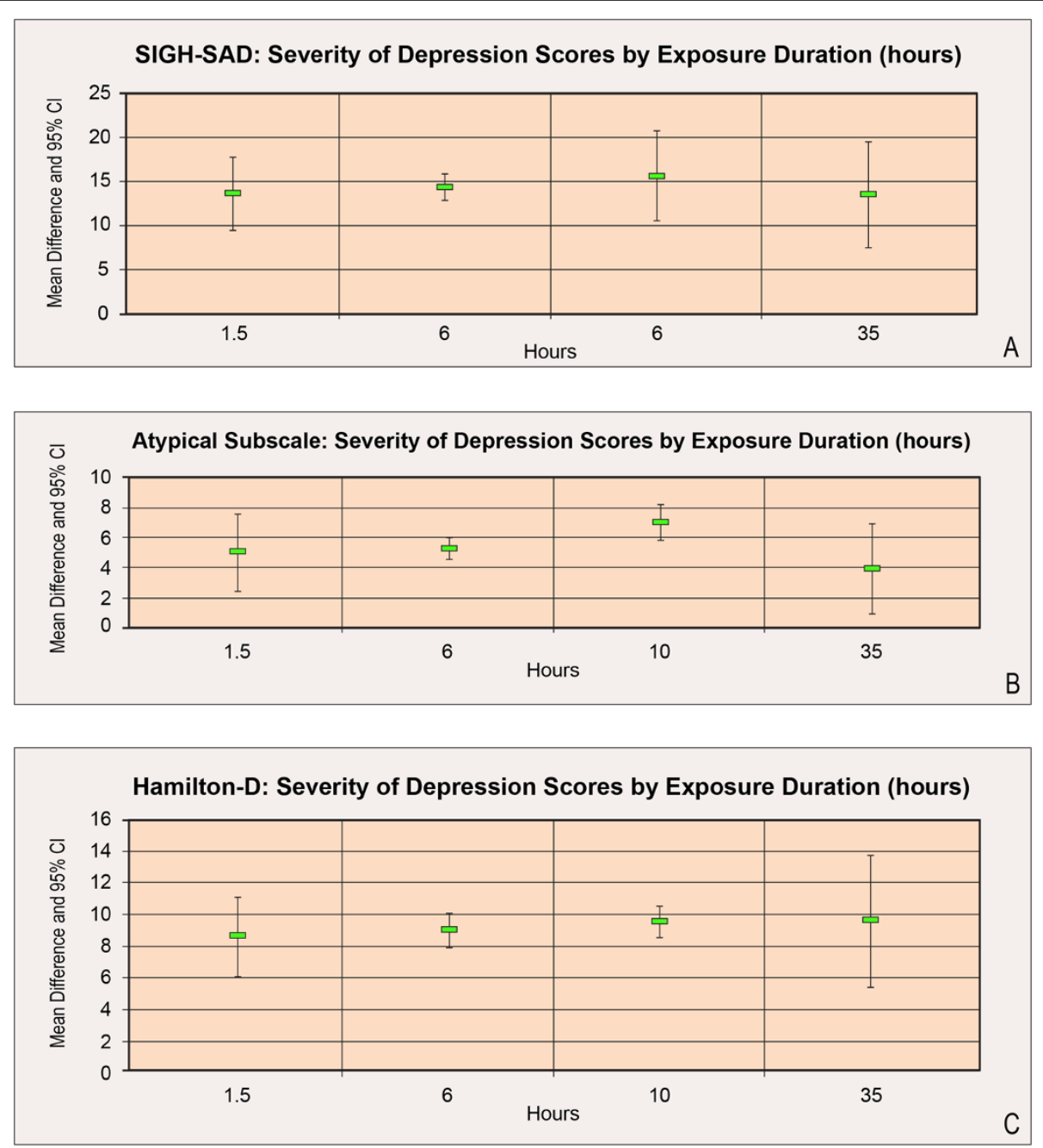

Figure 3 Dose-response Assessment Between Exposure Duration as Measured by Hours, within High-Density Air lon Levels, and Each Study's Score Mean Difference. *Terman, 1998 [8] only provided data for the composite SIGH-SAD scale and not by subscale; Terman and Terman [6] only provided data by subscale and not for the composite SIGH-SAD scale. 


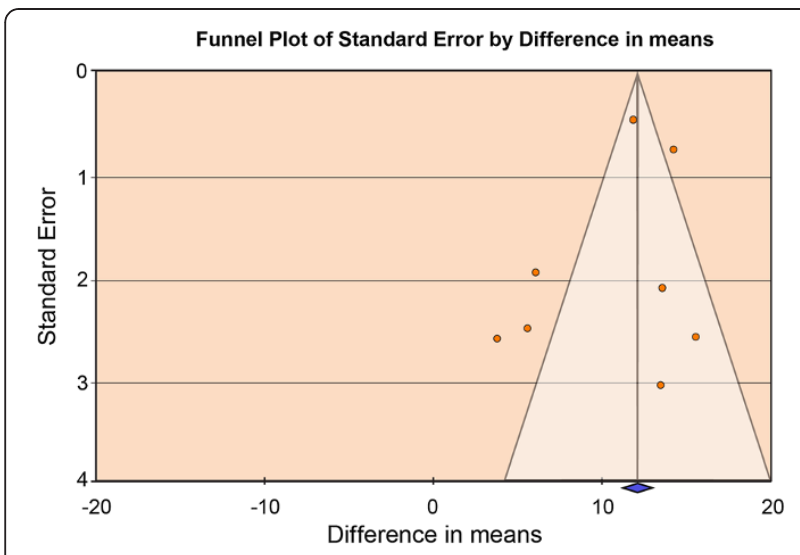

Figure 4 Visual Assessment of Publication Bias Using a Funnel Plot (SIGH-SAD composite scores). ${ }^{*}$ A clustering indicative of publication bias around the mean treatment effect was not observed (i.e., no marked asymmetry was evident). In the absence of publication bias we would expect the studies to be distributed symmetrically about the combined treatment effect.

symptom severity. Our main findings were two-fold. First, we failed to identify a consistent beneficial or detrimental effect of negative or positive air ionization on mental wellbeing based on studies of anxiety, mood, relaxation/sleep, and personal comfort. Second, our meta-analysis of five studies $[4,6-8,22]$ on negative air ionization and depression suggested a decreased severity of symptom scores in subjects with exposures to high air ion levels. Specifically, we observed a decrease in depression scores, thus corresponding to an improvement in subjects' depressive state, in comparisons of low- to high-density negative air ion exposure (weighted mean score decrease of 7.23 and 14.28 , respectively). A causal basis for this finding, however, was not presumed as the durations of exposure and depression scores were not dose-related.

Exposures to air ions in low dose conditions slightly, but significantly, reduced depression scores measured on the SIGH-SAD. Indeed, no study reported that low dose exposure produced a clinically significant reduction in depression (criterion applied by Terman et al. [8]; Flory et al. [4]; Terman and Terman [6]) of greater than $50 \%$. In fact, it appears that low dose ionization may be regarded by these investigators as an inactive exposure condition [22,24].

Although our meta-analysis showed that exposures to high levels of negative ions was associated with a significant improvement in rated depression severity as measured using SIGH-SAD, a primary metric for both seasonal and non-seasonal depression [4,43-46], and a lack of statistical heterogeneity across study results in the high-density analysis was observed, the findings should be cautiously interpreted. First, this body of work typically did not control for or failed to report on environmental factors affecting exposure including the electric field, air flow, humidity, and temperature. It is well known that the spatial distribution and numbers of air ions vary considerably due to differences in these factors [47]. Hence, the findings summarized herein are likely impacted by unmeasured variables within the available studies and the extent of this impact remains unknown. Second, air ion concentrations for high- and low-density were different across studies, ranging from $4.0 \times 10^{3}$ ions $/ \mathrm{cm}^{3}$ to $1.0 \times 10^{4}$ ions $/ \mathrm{cm}^{3}$ for lowdensity and from $2.7 \times 10^{6}$ ions $/ \mathrm{cm}^{3}$ to $2.7 \times 10^{7}$ ions/ $\mathrm{cm}^{3}$ for high-density (except for Flory et al. [4], who defined high-density as $\geq 2.0 \times 10^{6}$ ions $/ \mathrm{cm}^{3}$ ). Our finding of statistically significant heterogeneity across studies in the low-density analysis is likely impacted by these varying exposure levels, whereas the effect of high-density air ion treatment may occur independently of the range of exposure levels if an effective exposure threshold is exceeded. Given that at most two studies reported the same air ion concentrations for high- and low-density, however, we could not justify performing separate meta-analyses by ion concentration. However, when hours of exposure were considered as a surrogate for dose within the high- and low-density analyses, repeated or longer exposure durations to negative air ions failed to produce a greater effect on depression scores than did shorter durations. Third, all studies included in the meta-analysis except Flory et al. [4] were conducted by a single research group, which provides little independent replication and may explain, in part, the low between-study variance observed in the high-density analysis. Fourth, differential effects, if any, between men and women were not examined. Genderstratified analyses are important to consider given that the pharmacokinetics, pharmacodynamics, and hormonal effects between men and women differ and likely influence depression severity [48]. Finally, some depression studies $[5,24,29,31]$ included in our narrative review were unable to be meta-analyzed because of the heterogeneous reporting of available data and the use of different metrics for assessing depression (e.g., BDI and subjective assessments on the amelioration of 'depressive reactions'). Additional experiments are warranted to clearly understand the impact of negative air ionization on depression severity and how findings may be influenced by variable concentration levels and different metrics for symptom measurement. Future studies should aim to determine the efficacy of high-density air ion therapy for treating depression among men and women. Studies should also aim to evaluate the specificity of any response(s) to negative air ions by testing positive air ions as well.

Based on our review, there is no scientific basis for concluding that air ions have a beneficial or adverse effect on measures of anxiety, mood, relaxation/sleep, and personal comfort in the range of exposures reviewed (200-300 ions $/ \mathrm{cm}^{3}$ (ambient levels) to $10^{6}$ ions $/ \mathrm{cm}^{3}$ ). 
The quality of many studies, however, is low and there are several important inconsistencies across studies (e.g. differential study settings/populations, follow-up periods, exposure/outcome measurement and assessment, and unmeasured confounders such as temperature). Of particular importance is the heterogeneity observed in the frequency, duration, and intensity of air ionization evaluated. Presumably, the greater the ion concentration, combined with longer exposure durations at greater frequency, the greater the likelihood for air ion exposure to produce a biological response in exposed subjects, if in fact a real association is present. While there is no consistent support in animal studies for effects of negative or positive air ion treatment on central nervous system neurotransmitter systems linked to depression [21,49,50], Dowdall and De Montigny [51] have reported that continuous exposure of rats to negative air ions at a density of $1.5 \times 10^{6}$ ions $/ \mathrm{cm}^{3}$ for 21 days increases the response of hippocampal pyramidal neurons to iontophoretically applied serotonin as do several antidepressant drugs. Nonetheless, human studies to date on the relationship between exposure duration, within high and low air ion concentrations, and depression symptom severity do not support such a relationship. In addition, variable distances between subjects and the location at which ion generators were situated likely influenced the number of air ions reaching the subjects. Based on the exposure assessment alone, proper comparison across studies is therefore quite difficult due to the varying exposure assessments, differences in air ion systems used, and disparate monitoring of ion levels. A disparity in the measurement and assessment of the outcomes evaluated also renders a comparison across studies difficult. In this regard, instruments other than the SIGHSAD to measure depression severity (e.g., the BDI [52], the Center for Epidemiological Studies Depression Scale [53], the Zung Self-Rating Depression Scale [54]) might be considered in future studies since different depression scales may vary in sensitivity and specificity for depression severity, may differ in the measurement of different construct(s) based on the inclusion of specific survey items (i.e., items may discriminate between different dimensions of depression), and may be more suited over others in specific target populations (e.g., young adults vs. elderly patients). Furthermore, no study reported responses to air ion therapy by gender. Specific tests for differential responses, however, would have been of interest given that gender specific-differences are reported in the literature for many emotional parameters [55-57].

Though major limitations of the studies reviewed have been discussed, we acknowledge certain strengths. Since all studies were experimental, most, but not all, observations were made within a controlled environment and prospectively. In addition, participants in 2830 studies remained blind to exposure and ion density, thus mitigating potential bias. Blinding of the experimenters was less common (1618 of 2830). Such precautions should be taken in future studies to minimize introducing possible bias by subjects and investigators. In our review, subject expectations in some studies were compared with depression ratings at the study end. Some studies found no association between expectations and the outcome, suggesting minimal bias $[5,8]$, while other more recent studies reported a significant relationship $[4,7]$.

The World Health Organization conducted a communitybased study in 14 countries on the prevalence and severity of mood disorders and found that the 1-year prevalence of mood and anxiety disorders in developed nations ranged from $3.1 \%-5.3 \%$ in Japan to $9.6 \%-18.2 \%$ in the US [58]. Kessler et al. [59] used the National Comorbidity Survey Replication to estimate the lifetime prevalence of DSM-IV disorders and reported lifetime prevalence estimates for mood (20.8\%) and anxiety disorders (28.8\%). An earlier report by Kessler et al. [60] found that lifetime prevalence for clinical depression among US adults was $16.2 \%$ and 1-year prevalence was $6.6 \%$. Globally, the burden of mood disorders such as depression is on the rise, with only $30 \%$ of cases worldwide receiving appropriate care for depression [61]. Hence, mood and anxiety disorders present a global crisis that heavily burdens society with serious implications for daily quality of living, economic costs, and the need for individually-tailored treatment.

\section{Conclusions}

Our narrative review provides no basis for further investigation of a variety of emotional state indicators and air ionization. Our meta-analysis, however, strengthens the rationale for further study of high dose negative ionization $\left(>2.7 \times 10^{6}\right.$ ions $\left./ \mathrm{cm}^{3}\right)$ on depression severity, an effect, if real, that remains to be fundamentally understood. Such studies should apply a double-blind design with rigorous control over air ionization and potential confounding, including placebo effects. In addition, using validated metrics for outcome assessment in large study populations; determining justifiable thresholds to delineate between sham, low, and high air ion concentrations; and implementing an adequate exposure duration and follow-up period are recommended. Given that longer or repeated exposures to negative air ions were not observed to strengthen the response of subjects, additional investigation of the biological plausibility is warranted. The concentrations of air ions expressed as parts per trillion are vanishingly small and well-controlled animal studies do not report changes in catecholamine neurotransmitter levels [50] or the levels 
and turnover of serotonin in the brain [49] even though opposing effects of longer-term exposure to negative and positive air ions on the responsiveness of hippocampal neurons to serotonin have been reported [51].

\section{Competing interests}

WHB has consulted for AltaLink LLC, and public and private electric utilities in the preparation of environmental impact assessments and assisted scientific organizations, regulatory agencies, and health agencies to keep abreast of current research involving exposures relating to the use and transport of electricity.

\section{Authors' contributions}

WHB conceptualized the study and led the design, data acquisition, and interpretation. VP, DDA, and WHB collaborated on the data acquisition, analysis, and interpretation. VP drafted the manuscript. VP, DDA, and WHB provided critical revisions of the manuscript for important intellectual content. WHB provided supervision. All authors read and approved the final manuscript.

\section{Authors' information}

VP was awarded her Ph.D. in epidemiology from the University of Michigan at Ann Arbor. Her research primarily focused on the impact of psychological stress on the health of young adults in the community setting. DDA was awarded his Ph.D. in epidemiology from the University of Alabama at Birmingham. He has conducted numerous state-of-the-science reviews and weight-of-evidence assessments on complex medical and scientific issues. WHB was awarded his Ph.D. in neuropsychology from the City University of New York for research at The Rockefeller University, where he continued for postdoctoral research in neurochemistry. He has been involved in air ion research since 1982 and served as a science advisor to the Minnesota Environmental Quality Board and the Vermont Department of Public Service on health and safety issues relating to air ions.

\section{Acknowledgements}

The authors gratefully acknowledge the research contributions of Nancy Rivera in the preparation of this manuscript and the invaluable comments from Drs. Catherine Harmer and Timo Partonen.

\section{Funding}

This work was partially funded by a research grant from AltaLink LLC; however, the writing, data review, and interpretation were conducted independently by the authors.

\section{Author details}

'Exponent, Inc., Health Sciences, Center for Epidemiology, Biostatistics, and Computational Biology, 525 West Monroe Street, Suite 1050, Chicago, IL 60661, USA. '2Exponent, Inc., Health Sciences, Center for Epidemiology, Biostatistics, and Computational Biology, 4141 Arapahoe Avenue, Suite 101, Boulder, CO 80303, USA. ${ }^{3}$ Exponent, Inc., Health Sciences, Center for Exposure Assessment and Dose Reconstruction, 17000 Science Drive, Suite 200, Bowie, MD 20715, USA.

Received: 16 May 2012 Accepted: 8 January 2013 Published: 15 January 2013

\section{References}

1. Bracken TD: Small Air lon Properties. In Air lons: Physical and Biological Aspects. Edited by Charry JM, Kavet R. Boca Raton: CRC Press; 1987.

2. Bracken TD, Johnson GB: Small Air lon Environments. In Air lons: Physical and Biological Aspects. Edited by Charry JM, Kavet R. Boca Raton: CRC Press; 1987:13-21.

3. Chalmers JA: Atmospheric Electricity. New York: Pergamon Press; 1967.

4. Flory R, Ametepe J, Bowers B: A randomized, placebo-controlled trial of bright light and high-density negative air ions for treatment of Seasonal Affective Disorder. Psychiatry Res 2010, 177(1-2):101-108.

5. Goel N, Etwaroo GR: Bright light, negative air ions and auditory stimuli produce rapid mood changes in a student population: a placebocontrolled study. Psychol Med 2006, 36(9):1253-1263.
6. Terman M, Terman JS: Treatment of seasonal affective disorder with a high-output negative ionizer. J Altern Complement Med 1995, 1(1):87-92.

7. Terman M, Terman JS: Controlled trial of naturalistic dawn simulation and negative air ionization for seasonal affective disorder. Am J Psychiatry 2006, 163(12):2126-2133.

8. Terman M, Terman JS, Ross DC: A controlled trial of timed bright light and negative air ionization for treatment of winter depression. Arch Gen Psychiatry 1998, 55(10):875-882.

9. Malik M, Singh K, Singh M: Effect of negative air ions on physiological and perceived psychological stress during computer operation. Int $J$ Environment and Health 2010, 4:67-77.

10. Nakane $H$, Asami O, Yamada Y, Ohira H: Effect of negative air ions on computer operation, anxiety and salivary chromogranin A-like immunoreactivity. Int J Psychophysiol 2002, 46(1):85-89.

11. Assael M, Pfeifer $Y$, Sulman FG: Influence of artificial air ionisation on the human electroencephalogram. Int J Biometeorol 1974, 18(4):306-372.

12. Buckalew $L W$, Rizzuto A: Subjective response to negative air ion exposure. Aviat Space Environ Med 1982, 53(8):822-823.

13. Lips R, Salawu JT, Kember P, Probert SD: Intermittent exposures to enhanced air-ion concentrations for improved comfort and increased productivity? Applied Energy 1987, 28:83-94.

14. Misiaszek J, Gray F, Yates A: The calming effects of negative air ions on manic patients: a pilot study. Biol Psychiatry 1987, 22(1):107-110.

15. Charry JM, Hawkinshire FB: Effects of atmospheric electricity on some substrates of disordered social behavior. J Pers Soc Psychol 1981, 41(1):185-197.

16. Giannini AJ, Jones BT, Loiselle RH: Reversibility of serotonin irritation syndrome with atmospheric anions. J Clin Psychiatry 1986, 47(3):141-143.

17. McGurk F: Psychological effects of artificially produced air ions. Am J Phys Med 1959, 38:136-137.

18. Hedge A, Collis MD: Do negative air ions affect human mood and performance? Ann Occup Hyg 1987, 31(3):285-290.

19. Yaglou CP: Are Air lons a Neglected Biological Factor? In The Air We Breathe-A Study of Man and His Environment. Edited by Farber SM, Wilson R. Springfield, Illinois: Charles C. Thomas; 1961.

20. Charry JM: Biological Effects of Air lons: A Comprehensive Review of Laboratory and Clinical Data. In Air lons: Physical and Biological Aspects. Edited by Charry JM, Kavet R. Boca Raton: CRC Press; 1987:91-160.

21. Bailey WH, Bissell M, Brambl RM, Dorn CR, Hoppel WA, Sheppard AR, Stebbings JH: A Health and Safety Evaluation of the + / - 400 KV Powerline. St. Paul, MN: Minnesota Environmental Quality Board; 1982.

22. Goel N, Terman M, Terman JS, Macchi MM, Stewart JW: Controlled trial of bright light and negative air ions for chronic depression. Psychol Med 2005, 35(7):945-955.

23. Rothstein $\mathrm{H}$, Sutton A, Borenstein M: Publication Bias in Meta-Analysis: Prevention, Assessments, and Adjustments. John Wiley and Sons, Ltd; 2005.

24. Dauphinais DR, Rosenthal JZ, Terman M, DiFebo HM, Tuggle C: Rosenthal NE: Controlled trial of safety and efficacy of bright light therapy vs. negative air ions in patients with bipolar depression. Psychiatry Res 2012, 196(1):57-61.

25. Dantzler BS, Martin BG, Nelson HS: The effect of positive and negative air ions on bronchial asthma. Ann Allergy 1983, 51(3):362-366.

26. Giannini AJ, Giannini JD, Melemis S, Giannini JN: Treatment of acute mania with ambient air anionization: variants of climactic heat stress and serotonin syndrome. Psychol Rep 2007, 100(1):157-163.

27. Silverman $D$, Kornblueh $\mathbb{H}$ : Effect of artificial ionization of the air on the electroencephalogram; preliminary report. Am J Phys Med 1957, 36(6):352-358.

28. Baron RA, Russell GW, Arms RL: Negative ions and behavior: impact on mood, memory, and aggression among type A and type B persons. J Pers Soc Psychol 1985, 48(3):746-754.

29. Deleanu M, Stamatiu C: Influence of aeroionotherapy on some psychiatric symptoms. Int J Biometeorol 1985, 29(1):91-96.

30. Giannini AJ, Jones BT, Loiselle RH, Price WA: Anxiogenic effects of generated ambient cations--a preliminary study. Int J Psychiatry Med 1986-87, 16(3):243-248.

31. Harmer CJ, Charles M, McTavish S, Favaron E, Cowen PJ: Negative ion treatment increases positive emotional processing in seasonal affective disorder. Psychol Med 2012, 42(8):1605-1612.

32. Malcolm CP, Cowen PJ, Harmer CJ: High-density negative ion treatment increases positive affective memory. Psychol Med 2009, 39(11):1930-1932.

33. Reilly T, Stevenson IC: An investigation of the effects of negative air ions on responses to submaximal exercise at different times of day. $J$ Hum Ergol (Tokyo) 1993, 22(1):1-9. 
34. Tom G, Poole MF, Galla J, Berrier J: The influence of negative air ions on human performance and mood. Hum Factors 1981, 23(5):633-636.

35. Watanabe I, Noro H, Ohtsuka Y, Mano Y, Agishi Y: Physical effects of negative air ions in a wet sauna. Int J Biometeorol 1997, 40(2):107-112.

36. Giannini AJ, Jones BT, Loiselle RH, Price WA: Anxiogenic effects of generated ambient cations--a preliminary study. Int I Psychiatry Med 1986-1987, 16(3):243-248.

37. Albrechtsen O, Clausen V, Christensen FG, Jensen JG, Moller T: The influence of small atmospheric ions on human well-being and mental performance. Int J Biometeorol 1978, 22(4):249-262.

38. Hawkins $L H$ : The influence of air ions, temperature and humidity on subjective wellbeing and comfort. J Environ Psych 1981, 1:279-292.

39. Iwama $\mathrm{H}$, Ohmizo H, Obara S: The relaxing effect of negative air ions on ambulatory surgery patients. Can J Anaesth 2004, 51(2):187-188.

40. Finnegan MJ, Pickering CA, Gill FS, Ashton I, Froese D: Effect of negative ion generators in a sick building. Br Med J (Clin Res Ed) 1987, 294 (6581):1195-1196.

41. Harmer CJ, Cowen PJ, Goodwin GM: Efficacy markers in depression. J Psychopharmacol 2011, 25(9):1148-1158.

42. Harmer CJ, O'Sullivan U, Favaron E, Massey-Chase R, Ayres R, Reinecke A, Goodwin GM, Cowen PJ: Effect of acute antidepressant administration on negative affective bias in depressed patients. Am J Psychiatry 2009, 166(10):1178-1184.

43. Leppamaki S, Haukka J, Lonnqvist J, Partonen T: Drop-out and mood improvement: a randomised controlled trial with light exposure and physical exercise [ISRCTN36478292]. BMC Psychiatry 2004, 4:22.

44. Loving RT, Kripke DF, Shuchter SR: Bright light augments antidepressant effects of medication and wake therapy. Depress Anxiety 2002, 16(1):1-3.

45. Partonen T, Leppamaki S, Hurme J, Lonnqvist J: Randomized trial of physical exercise alone or combined with bright light on mood and health-related quality of life. Psychol Med 1998, 28(6):1359-1364.

46. Wileman SM, Eagles JM, Andrew JE, Howie FL, Cameron IM, McCormack K, Naji SA: Light therapy for seasonal affective disorder in primary care: randomised controlled trial. Br J Psychiatry 2001, 178:311-316.

47. Charry JM: Biological effects of small air ions: a review of findings and methods. Environmental Research 1984, 34:351-389.

48. Weinberger AH, McKee SA, Mazure CM: Inclusion of women and gender-specific analyses in randomized clinical trials of treatments for depression. J Womens Health (Larchmt) 2010, 19(9):1727-1732.

49. Bailey $\mathrm{WH}$, Charry JM: Acute exposure of rats to air ions: Effects on the regional concentration and utilization of serotonin in brain. Bioelectromagnetics 1987, 8:173-181.

50. Charry JM, Bailey WH: Regional turnover of norepinephrine and dopamine in rat brain following acute exposure to air ions. Bioelectromagnetics 1985, 6:173-185

51. Dowdall $M$, De Montigny C: Effect of atmospheric ions on hippocampal pyramidal neuron responsiveness to serotonin. Brain Res 1985, 342(1):103-109.

52. Beck AT, Ward CH, Mendelson M, Mock J, Erbaugh J: An inventory for measuring depression. Arch Gen Psychiatry 1961, 4:561-571.

53. Radloff LS: The CES-D scale: A self-report depression scale for research in the general population. Appl Phsychological Measurement 1977, 1:385-401.

54. Zung WW: A self-rating depression scale. Arch Gen Psychiatry 1965, 12:63-70

55. Afifi M: Gender differences in mental health. Singapore Med J 2007 48(5):385-391.

56. McRae K, Ochsner K, Mauss I, Gabrieli J, Gross J: Gender differences in emotion regulation: An $\mathrm{fMRI}$ study of cognitive reappraisal. Group Processes \& Intergroup Relations 2008, 11:143-162.

57. Vigil JM: A socio-relational framework of sex differences in the expression of emotion. Behav Brain Sci 2009, 32(5):375-390. discussion 391-428.

58. Demyttenaere K, Bruffaerts R, Posada-Villa J, Gasquet I, Kovess V, Lepine JP, Angermeyer MC, Bernert S, de Girolamo G, Morosini P, et al: Prevalence, severity, and unmet need for treatment of mental disorders in the World Health Organization World Mental Health Surveys. JAMA 2004, 291(21):2581-2590

59. Kessler RC, Berglund P, Demler O, Jin R, Merikangas KR, Walters EE: Lifetime prevalence and age-of-onset distributions of DSM-IV disorders in the
National Comorbidity Survey Replication. Arch Gen Psychiatry 2005, 62(6):593-602.

60. Kessler RC, Merikangas KR, Berglund P, Eaton WW, Koretz DS, Walters EE: Mild disorders should not be eliminated from the DSM-V. Arch Gen Psychiatry 2003, 60(11):1117-1122.

61. World Health Organization: Conquering Depression. Lyons: World Health Organization, Regional Office for Southeast Asia; 2001.

doi:10.1186/1471-244X-13-29

Cite this article as: Perez et al:: Air ions and mood outcomes: a review and meta-analysis. BMC Psychiatry 2013 13:29.

\section{Submit your next manuscript to BioMed Central and take full advantage of:}

- Convenient online submission

- Thorough peer review

- No space constraints or color figure charges

- Immediate publication on acceptance

- Inclusion in PubMed, CAS, Scopus and Google Scholar

- Research which is freely available for redistribution 